\title{
Recent Developments in Obesity Research: Linkages between Obesity, Disability, and Physical Functioning
}

\author{
Sandra L. Reynolds
}

Published online: 5 June 2013

(C) Springer Science+Business Media New York 2013

\begin{abstract}
In the last several decades, the literature on obesity has increased exponentially. In spite of growing interest in trends in obesity worldwide, we remain largely in the dark regarding the true nature of the causes and consequences of obesity. High weight is clearly a risk factor for a variety of negative health outcomes; indeed, obesity is one of the clearest negative health trends to emerge in the last half of the twentieth century. What continues to elude us is the mechanism by which obesity impacts health and functioning, a critical distinction which must precede the development of effective interventions.
\end{abstract}

Keywords ADL disability · Morbidity · Sarcobesity · Obesity $\cdot$ Disability $\cdot$ Physical functioning

\section{Introduction}

In the latter part of the twentieth century, the increase in both childhood and adult obesity has garnered a great deal of attention. According to the Centers for Disease Control, while obesity in American children aged 2 through 5 remained essentially flat between 1999 and 2007, there has been an increase for both boys and girls in ages 6 through 19 [1]. In adults aged 20 and older, trends during the same period also have been upward, with the greatest increase and highest prevalence in the 60-69 year age group [2, 3••]. Longer term trends have been even more remarkable; between 1972 and 2010, the prevalence of adult obesity has increased approximately $150 \%$ [2]. During the same period, research into obesity, as measured by the number of citations in Medline, has increased approximately $550 \%$. Figure 1 shows the exponential nature of the growth in Medline Citations using

S. L. Reynolds $(\square)$

USF School of Aging Studies, University of South Florida, 4202 E. Fowler Ave., MHC 1300, Tampa, FL 33620, USA e-mail: sreynold@usf.edu

URL: http://agingstudies.cbcs.usf.edu/faculty/sreynolds.cfm 'obesity' as the keyword between 1972 and 2012. Not surprisingly, the increase in research into obesity follows the increase in obesity - in this case, the average proportion of adult obesity in the United States between 1972 and 2010-by approximately 10 years.

In spite of the virtual explosion of interest in the 'obesity epidemic' [4], we remain largely in the dark regarding the true nature of the causes and consequences of obesity. High weight is clearly a risk factor for a variety of negative health outcomes; indeed, obesity is one of the clearest negative health trends to emerge in the last half of the twentieth century. What continues to elude us is the mechanism by which obesity impacts health and functioning, a critical distinction which must precede the development of effective interventions. The purpose of this article is to examine recent research on obesity and its impact on disability and physical functioning. An extensive sample of the obesity research published since 2012 has yielded several outstanding issues, concerning obesity, disability, and physical functioning in children and adults, in the general population and in those with specific conditions. These issues include causes and consequences of obesity, continuing debate about appropriate measures of obesity, and increasing interest in the development and prevention of sarcobesity.

\section{Measuring Obesity}

The continuing problem with measuring obesity involves natural trade-offs between quantity and quality of data. Population-based surveys, such as the National Health Interview Surveys and Health and Retirement Surveys, conducted in the United States (US) have generally had to limit the measurement of obesity to body mass index (BMI) from selfreports of height and weight. In contrast, the National Health and Nutrition Examination Surveys (NHANES) have used measured height and weight, waist and arm circumference, and measures of skinfold thickness. The NHANES uses dual x-ray absorptiometry (DEXA), which can be used to measure 
Fig. 1 Increase in obesity citations and prevalence of obese U.S. Adults, 1972-2012

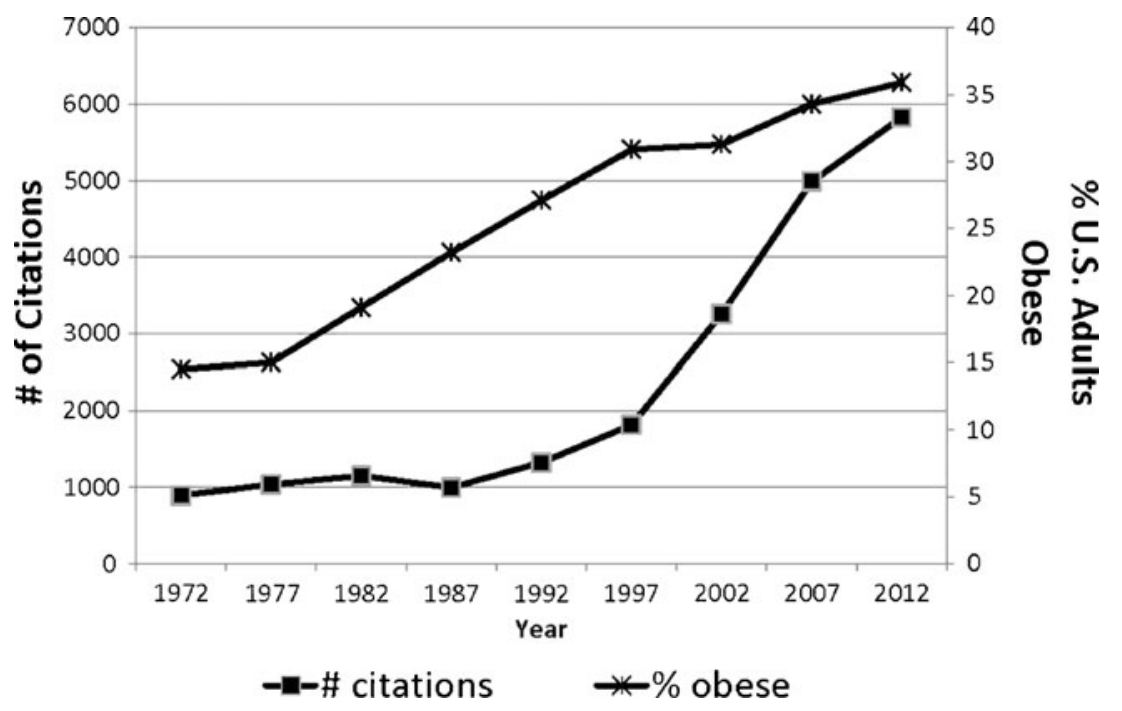

body composition, but NHANES only records the measures of spine and femur composition [5]. For more sophisticated measures of obesity (e.g., fat mass, muscle mass), clinical surveys are much more practical, with the trade-off being smaller and less representative samples.

Recent research provides several examples of this issue. While nearly all of the articles surveyed use either selfreported or measured height and weight to calculate BMI, several studies use multiple measures, most often in an attempt to distinguish which of the chosen measures provides the best predictive value for a specified outcome. Alternatives to BMI have included intra-abdominal fat (IAF; measured by ultrasound), and body composition measures such as fat mass, fat free mass, waist and hip circumference, and waist/hip ratio, usually measured by DEXA $[6-10,11 \bullet, 12 \bullet, 13,14 \bullet \cdot]$. Only one of these studies eliminated BMI as a measure of obesity [10], as the results indicated that total and leg lean mass were linked to pain disability, while BMI was not. Others found significant effects of BMI and IAF [9], interactive effects of high $\mathrm{WC}$ and $\mathrm{BMI}=>30[11 \bullet]$, and gender-specific results in

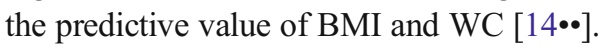

The variety in these results emphasizes the importance of understanding the implications of how we measure obesity. Among other things, we have relatively little insight into the relationships the various measures have with each other [13]. In addition, in at least one study of weight loss and exercise as interventions, results clearly indicate that measuring BMI is not enough, and should include such measures as fat and muscle mass $[12 \bullet \bullet]$.

\section{Obesity and Disability in Adults}

The connection between adult obesity and disability is welldocumented [15-23], usually finding significant effects of obesity on activities of daily living (ADL) disability. ADLs include personal care tasks, such as bathing, dressing, feeding oneself, toileting, transfer, and walking inside one's home [24]. Among population-based studies finding significant obesity effects, a Swiss study of nursing home residents [25] using Minimum Dataset Resident Assessment Interview (MDSRAI) data found that those who were underweight or overweight had increased need for ADL care, while those who were obese were the least likely to experience recovery over the ten-year period. These findings are mitigated somewhat by the already impaired sample, and dependence on the accuracy of staff input on the MDSRAI. In another population-based study, this one done in Spain, adults were examined for the onset of ADL, IADL, and mobility disability [26]. Results were gender-specific--obesity was found to be linked to ADL disability and mobility disability in women. Only being a smoker predicted ADL disability in men [26]. Also using a population-based study, Stafford and colleagues [27] examined two waves of the Health Survey for England, looking for socioeconomic status (SES) differences in the health-rated quality of life (QOL) impact of cardiovascular conditions (CVD). Using the EuroQOL EQ-5D scale [28], which includes mobility, self-care (ADLs), and usual activities domains, the authors found CVD risk highest in low SES respondents, and this effect was significantly exacerbated by obesity. Unfortunately, the authors did not present domainspecific results, so we cannot tell the precise nature of the impact of obesity on ADLs, for example.

While ADL disability was the most frequent type of disability examined, some studies chose other types of disability, including work disability. Arterburn and colleagues' study, which sought the relationship between obesity, depression and seven domains of disability, including work limitations, found that depression was associated with all seven domains, while obesity was associated with rolefunctioning, household, and work limitations [29•]. In addition, a longitudinal German study of construction workers aged 25-64 examined the onset of occupational disability, a 
measure similar to work disability [30]. Both baseline BMI and increased BMI were related to onset of occupational disability, by $10 \%$ and $26 \%$, respectively.

Among studies that did not find a relationship between obesity and disability was a longitudinal study of older adults in São Paulo, Brazil [31•]. This study's findings indicated that BMI was not a significant predictor of the onset of ADL disability. In a survey of college alumni aged 60 and older, "abnormal weight", smoking and sedentary lifestyle were examined for both survival and disability onset over a period of 20 years [32]. Abnormal weight was not a significant predictor of disability; in fact, smoking trumped all other factors. Unfortunately, in addition to a clearly non-representative sample, the authors combined underweight and overweight together (abnormal weight), almost certainly diluting any results one might expect.

Finally, several studies examined the impact of different measures of obesity on disability in adults. In a Dutch study of middle-age and older adults, denOuden and colleagues used BMI and IAF to examine their associations with ADL and IADL disability, finding that higher levels of BMI and lower levels of IAF were both associated with having 'any grade of dependence' on any of the disability questions [9]. Using the Health, Well-being and Aging in Latin America and the Caribbean study (SABE) data from 1999-2000, Nam and colleagues examined adults age 65 and older in seven cities $[11 \bullet, 33]$. Combining BMI and WC into six categories (e.g., low WC with overweight, low WC with obesity), significant results were found in some of the cities, with the High WC with overweight and high WC with obesity groups the most likely to be associated with ADL disability. Similarly, a longitudinal study of Australian adults used BMI, WC, hip circumference (HC), waist-hip ratio (WHR), fat mass, fat free mass and $\%$ fat, to predict ADL disability [14••]. Findings in men indicate that BMI is the best predictor of all types of disability, with WC nearly as good. In women, BMI and WC together were the strongest predictors of overall and mobility disability, and $\mathrm{HC}$ was the best predictor of self-care disability.

While these recent studies tend to confirm a relationship between obesity and disability in adults, the evidence is by no means consistent. Comparison of results is complicated by differing definitions of disability and obesity, sample sizes, and methods of data collection. In general, these difficulties also plague studies examining obesity and physical functioning in adults.

\section{Obesity and Physical Functioning in Adults}

Research results addressing linkages between obesity and physical functioning (PF) are only marginally more consistent. Several studies indicated deleterious effects of obesity on several measures of PF, such as the Physical Component Scale
(PCS) of the Short Form Health Status Measures (SF36), upper and lower body limitations, timed walking tests, among others [15].

Several population-based studies found significant linkages between obesity and PF. For example, Levine and Crimmins examined a nationally representative sample of US adults 60 and older to observe the relationship between obesity and sarcopenia on the ability to perform six measures of PF [34••]. Cross-sectional results showed that obesity had a significant negative effect on PF with and without the presence of sarcopenia. In another population-based study, $\mathrm{Oh}$ and colleagues studied the relationship between obesity and upper and lower limb functioning [35]. Their findings suggested a strong link between lower limb difficulty and obesity, but no relationship between obesity and upper limb difficulty. The previous two studies [34••, 35] were crosssectional, so causal inferences cannot be drawn. In contrast, a 3 -year longitudinal study was conducted on nearly 68,000 post-menopausal women to examine whether obesity was a predictor of change in the PCS of the SF36 [36]. Results suggest that both overweight and obesity are associated with a $32 \%$ and $38 \%$ greater likelihood of worse functioning, respectively.

Other studies examined PF and obesity in purposive or clinical samples. In a study of relatively affluent urban Brazilian women, Vagetti used the ability to participate in physical activities as the measure of PF, and found no relationship between BMI and the physical activity ability [37]. Other studies, including a survey of older homebound Israelis [38], fibromyalgia patients undergoing interdisciplinary treatments [39], gastric bypass patients [40], and middle-aged members of Kaiser Permanente with no COPD [41], found somewhat consistent results, with all four of these finding that obesity is associated with worse PF. Subtle differences in the study findings, however, include a finding that both underweight and obesity impaired PF [38], increasing or severe obesity (BMI 35+) impaired PF [39, 40], and in one case, that the greater culprit was smoking [41]. All of these samples, of course, were relatively small and non-representative.

As with obesity and disability, there is strong evidence that obesity negatively impacts PF in adults. Drawing firm conclusions from these results is problematic due to measurement issues, sample sizes, and data collection methods. In many ways, these issues are even more complicated when examining obesity in children and adolescents.

\section{Childhood Obesity and Disability}

Increasing overweight and obesity in US children has also become a major concern for public health policy makers, and consequently has received increasing attention by the research community. In spite of an apparent leveling off in recent years, 
nearly one-third of US children, aged 2-17, are overweight or more, and there are significant disparities by socioeconomic status, race and ethnicity [1]. The most recent estimates of high weight in US children indicate that $19.6 \%$ of children aged 611 are overweight $(=>85$ th percentile on CDC's sex-specific BMI for age growth charts), and $35.5 \%$ of children aged 6-11 are obese [1]. Comparisons to subpopulations of children reveal significant differences in being overweight among white, black, and Hispanic children aged 6 to 11, with $34.5 \%$ overweight in non-Hispanic white children, $37.6 \%$ in non-Hispanic black children, and $42.6 \%$ in Hispanic children [1].

Of course, obesity in children is not an issue limited to the US. In a longitudinal study in the United Kingdom, Deere and colleagues examined adolescents under the age of 17 for the types of pain commonly associated with fibromyalgia in adults [42•]. Using measured BMI and the 95th percentile cutoff, they found that obese adolescents were more likely to report most types of pain compared to their non-obese peers. Although headache pain is associated with obesity in adults [43], it is rarely addressed in children. However, in an Italian review of studies on migraine headaches in children, Verrotti and colleagues observed a clear connection between obesity and migraines, which are often a disabling condition [44]. They also found evidence in the literature of potential mechanisms, such as inflammatory adipocytokines including tumor necrosis factor- $\alpha$ and interleukin- 6 which are elevated in obese persons and may, in turn, increase the incidence of migraines.

As children mature, issues of weight assume an increasing saliency for self-esteem and other psychosocial issues. Using a nationally representative sample from the US National Survey of Children's Health, researchers compared 43,000 children from ages 10 to 17 to determine whether being overweight or obese was linked to disability [45••]. The measure used was a parent-report of whether the child was limited or prevented from doing the kinds of activities that most children of the same age can do. Using the 85th percentile for overweight and the 95th for obese BMI cutoffs, the authors found evidence of a link between obesity and activity restrictions and an increased tendency toward poorer health, emotional problems (such as bullying), and other school-related problems. This crosssectional study raises the issue of whether high weight precedes or is the result of these physical or emotional difficulties. In another study of mental health related issues, Ranzenhofer and colleagues examined obese (95th percentile of BMI) nonHispanic White and non-Hispanic Black children between the ages of 12 and 17 [46]. The purpose of the study was to examine a specific emotional eating behavior - binge eating - and its association with QOL. In adults, it is fairly wellestablished that binge eating is connected to lower mental and physical QOL [47]. The Impact of Weight Quality of Life measure [48], adapted for use with adolescents examined seven domains of weight-related QOL, with results indicating that binge eating was associated with poorer QOL in the domains of health, mobility, and self-esteem. Gender-specific results showed a higher propensity for the females to report lower QOL than males in activities of daily living, mobility, self-esteem, social/interpersonal functioning, and problems in school.

While these studies implicate obesity in a variety of physical and mental health disabilities, many factors remain to be examined. Such factors include family dynamics, particularly nutritional eating habits, and social and environmental context [49॰].

\section{Obesity, Osteoarthritis, and Treatment Outcomes in Adults}

Obesity puts adults and children at elevated risk for a variety of chronic conditions, including osteoarthritis (OA), diabetes, heart disease, and stroke, any one of which can be a risk for disability, workplace injuries, pain, and difficulty in physical functioning [50-53]. Recent research suggests that the combination of obesity and OA is a risk factor for quality of life, particularly in older adults $[10,54,55 \bullet, 56 \bullet$. Messier [57] suggests that $\mathrm{OA}$ of the knees and hips is linked to obesity because of the mechanical stress obesity places on weightbearing joints, a suggestion buttressed by the lack of any findings of obesity effects on $\mathrm{OA}$ in the hands, for example. In a meta-analysis of obesity and OA studies, Jiang and colleagues found that, on average, a 5-unit increase in BMI was associated with a $35 \%$ greater likelihood of knee OA [58]. As with any meta-analysis, the results are highly dependent on the inclusion and exclusion criteria used. Nevertheless, other studies tend to confirm this relationship. A Korean study found that high BMI in adults with knee OA-regardless of severity-had a significant negative effect on physical performance, as measured by the Short Physical Performance Battery [59]. Other important factors included muscle strength and the presence of knee pain [60•]. Similarly, a Dutch review of the OA literature found that high BMI combined with a low level of physical functioning were related to the lowest levels of physical activity in adults in hip OA [61].

Another issue involving obesity and OA relates to the efficacy of treatment. Vincent and colleagues recently summarized both mechanisms through which obesity impacts the etiology of OA, and the efficacy of weight loss treatments to ameliorate and/or prevent OA [55••, 56••]. To begin, obesity puts abnormal strain on weight-bearing joints, resulting in joint compression and malalignment. A complicating factor is the higher muscle mass and fat mass in obese people, which increases both systemic and local inflammation factors, such as Il- 6 , tumor necrosis factor- $\alpha$, and C-reactive protein (CRP). The combination of joint degeneration and increased inflammation leads to pain, decreased function, and OA. In older adults, this process can lead to a vicious 
downward cycle also recognized in the propensity to fall; pain associated with OA leads to decreased physical activity, which in turn leads to higher weight, which increases pain and further joint deterioration, and so on $[55 \bullet \bullet, 56 \bullet \bullet, 62]$.

In order to break this cycle, weight loss interventions commonly used are medications, diet and exercise, and bariatric surgery in extreme cases. All of these interventions carry risks, particularly bariatric surgery, and the research is not clear in terms of their short- or long-term effectiveness. In spite of their potential to generate positive health and economic benefits [63•], evidence that weight-loss medications are effective in the long-term is lacking. Even then research indicates that even in the short-term, weight-loss medications may help less than half of those who take them, and are probably more effective when used in combination with diet and exercise [56••]. Diet and exercise as interventions have been examined in many randomized controlled trials, with fairly consistent results indicating at least an additive effect between the two, not only in the ability to lose weight, but also in decreased pain associated with OA [55••]. In a particularly interesting study of diet and nutrition, Park and colleagues examined the Korean diet (high in salt, additives, and sugar) for effects on the behavior of Korean school children [64]. While obesity itself was not addressed, they found a strong link between diet, nutrition and both learning disabilities and attention-deficit/hyperactivity disorder.

In addition, Henriksen's study of weight loss in obese patients with knee OA raises the question of how best to lose weight, particularly in older adults, for whom weight loss can be evidence of deteriorating health, and can also lead to the onset of sarcopenia [10]. In fact, one of the more intriguing developments in obesity research relates to the combination of obesity and sarcopenia, commonly known as sarcobesity.

\section{Sarcobesity - An Emerging Issue for Older Adults}

Sarcopenia is defined as age-related loss of muscle mass, a condition that affects over $33 \%$ of adults over the age of 60 , and more than half of those aged 80 and older [12••]. The presence of sarcopenia in older adults is associated with mobility and frailty, joint disorders, loss of physical strength, and functional capacity. The combination of obesity and sarcopenia - sarcobesity (SO) - can be particularly disabling, as obesity elevates the risk of chronic conditions, such as impaired glucose regulation, depression, and myriad cardio- and cerebro-vascular conditions $[12 \bullet \bullet, 34 \bullet \bullet, 65]$. In a study of elderly Taiwanese, Lu and colleagues [65] examined the connection between $\mathrm{SO}$ and metabolic syndrome, using measures from the National Cholesterol Education Program-Adult Treatment Panel III, modified for Asians [66]. BMI and skeletal muscle mass were combined to create four categories of interest: 1) normal; 2) sarcopenia; 3) obesity; and 4) SO. Their findings suggest that SO places older adults at a much greater risk of metabolic syndrome than either sarcopenia or obesity alone. These results are extended in the study by Levine and Crimmins, who used 1999-2004 NHANES data to examine the relationship between obesity and sarcopenia on the ability to perform six measures of PF [34.•], including walking a quarter mile, climbing ten stairs, and other similar tasks. Using standard gender-specific measures of High WC [67] and sarcopenia, they found an additive effect, with greater likelihood of PF difficulty of $30 \%, 55 \%$, and $83 \%$ with obesity, sarcopenia and SO, respectively [34••].

Addressing weight loss in older adults must be approached cautiously, then, in order to improve the weight without risking the development of sarcopenia. There is considerable evidence that preventing SO in older adults is a complex process, and at the very least should involve aerobic exercise, strength training, proper diet and adequate nutrition in order to preserve muscle mass $[12 \bullet \bullet, 55 \bullet \cdot]$. This confluence of weight loss methods has been shown to lessen such critically important chronic health factors as inflammation, oxidative stress, and insulin resistance $[34 \cdot \bullet, 55 \cdot \bullet]$, and to increase muscle strength with the potential to ameliorate physical symptoms in patients with conditions as diverse as knee $\mathrm{OA}$ and multiple sclerosis $[60 \bullet, 68]$.

\section{Conclusion}

In summary, even though there is occasionally conflicting evidence, the recent literature on obesity confirms previously established connections between disability, physical functioning, and obesity in children and adults. As one of the clearest negative health trends to emerge worldwide in the latter half of the twentieth century, the prospects for increasing disability are alarming $[1,2,3 \bullet \bullet, 15,69]$. As this trend continues, areas of particular concern are increased diagnosis of type II diabetes in children and a potential reversal of positive trends in disability and chronic conditions, particularly among middle-age adults [19, 20, 70-72].

In addition to vexing issues concerning the measurement of obesity, research into disability and physical functioning is also hampered by differing definitions of both concepts. In spite of efforts to standardize these measures [73], inconsistencies persist, making it difficult to determine trends accurately, and to compare results between studies. Compounding this problem are differences in the nature of samples used in studies of obesity - clinical vs. population; general vs. disease-specific - and a variety of methods - primary vs. secondary data; crosssectional vs. longitudinal, for example. While these differences are driven by the aims of different research projects, 
this also hampers our ability to make comparisons across studies, much less across countries.

The main limitation of this review is that, given the trends cited in Fig. 1, it goes without saying that this article represents but a sample of recent studies of obesity. Observations made, therefore, are dependent on the studies chosen for review. Nevertheless, there is no reason to assume that conclusions drawn are anything but robust.

Perhaps the most encouraging developments are studies addressing mechanisms leading to obesity. Studies examining inflammation, adipocytokines, vitamin $\mathrm{D}$, and other biophysical elements hold great promise for informing further studies of the etiology of obesity [55••, 56••, 74, 75]. Understanding of these and other underlying mechanisms is key to the development of effective, long-lasting interventions designed to halt, or at least, slow the increase in obesity that currently plagues society worldwide.

\section{Compliance with Ethics Guidelines}

Conflict of Interest Sandra L. Reynolds declares that she has no conflict of interest.

Human and Animal Rights and Informed Consent This article does not contain any studies with human or animal subjects performed by any of the authors.

\section{References}

Papers of particular interest, published recently, have been highlighted as:

- Of importance

•- Of major importance

1. Ogden CL, Carroll MD, Curtin LR, et al. Prevalence of high body mass index in US children and adolescents, 2007-2008. JAMA. 2010;303:242-9.

2. Flegal KM, Ogden CL, Carroll MD, Johnson CL. Prevalence and trends in obesity among US adults, 1999-2000. JAMA. 2002;288:1723-7.

3. •• Flegal KM, Carroll MD, Kit BK, Ogden CL. Prevalence of obesity and trends in the distribution of body mass index among US adults. JAMA. 2012;307:491-7. doi:10.1001/jama.2012.39. We showed that increasing trends in US adult obesity include age-specific differences.

4. Mokdad AH, Serdula MK, Dietz WH, et al. The spread of the obesity epidemic in the United States, 1991-1998. JAMA. 1999;282:151922. doi:10.1001/jama.282.16.1519.

5. NCHS. National Health and Nutrition Examination Survey. Available at: http://www.cdc.gov/nchs/nhanes.htm, accessed 2/13/13.

6. Ozbey N, Sencer E, Molvalilor S, Orhan Y. Body fat distribution and cardiovascular disease risk factors in pre- and post-menopausal women with the same BMI. Endocr J. 2002;49:503-9.

7. Apovian CM, Frey CM, Wood GC, et al. Body mass index and physical functioning in older women. Obes Res. 2002;10:740-7.

8. Davison KK, Ford ES, Cogswell ME, Dietz WH. Percentage body fat and body mass index are associated with mobility limitations in people 70 and older from NHANES III. J Am Geriatr Soc. 2002;50:1802-9.

9. den Ouden MEM, Schuurmans MJ, Mueller-Schotte S, et al. Domains contributing to disability in activities of daily living. JAMDA. 2013;14:18-24. doi:10.1016/jamda.2012.08.014.

10. Henriksen M, Christensen R, Danneskiold-Samsøe B, Bliddal H. Changes in lower extremity muscle mass and muscle strength after weight loss in obese patients with knee osteoarthritis: a prospective cohort study. Arth Rheum. 2012;64:438-42. doi:10.1002/art.33394.

11. - Nam S, Kuo Y-F, Markides KS, Al Snih S. Waist circumference (WC), body mass index (BMI), and disability among older adults in Latin America and the Caribbean (LAC). Arch Geront Geriatr. 2012;55:e40-7. doi:10.1016/j.archger.2012.04.006. We found the combination of waist circumference and both overweight or obesity to predict ADL disability.

12. •• Parr EB, Coffey VG, Hawley JA. 'Sarcobesity': a metabolic conundrum. Maturitas. 2013;74:109-13. doi:10.1016/ j.maturitas.2012.10.014. We endorse current evidence that strongly supports the combination of resistance and aerobic exercise with weight-loss techniques to avoid loss of muscle and prevent sarcobesity.

13. Rizk A, Gheita TA, Nassef S, Abdallah A. The impact of obesity in systemic lupus erythematosus on disease parameters, quality of life, functional capacity and the risk of atherosclerosis. Int J Rheum Dis. 2012;15:261-7.

14. •• Wong EW, Stevenson C, Backholer K, et al. Adiposity measures as predictors of long-term physical activity. Ann Epidem. 2012;22:710-6. doi:10.1016/j.annepidem.2012.07.009. We found that body mass index, waist circumference, and in women, hip circumference, were superior to waist-hip ratio, fat mass, fat free mass, and percent fat in predicting ADL disability.

15. Ware JE, Snow KK, Kosinski M, Gandek B. SF-36 health survey manual and interpretation guide. New England Medical Center. Boston, MA: The Health Institute; 1993.

16. Reynolds SL, Saito Y, Crimmins EM. The impact of obesity on active life expectancy in older American men and women. Gerontologist. 2005;45:438-44. doi:10.1093/geront.45.4.438.

17. Jenkins KR. Obesity's effect on the onset of functional impairments among older adults. Gerontologist. 2004;44:206-16. doi:10.1093/ geront/44.2.206.

18. Peeters A, Bonneux L, Nusselder WJ, et al. Adult obesity and the burden of disability throughout life. Obes Res. 2004;1145-51.

19. Himes CL. Obesity, disability, and functional limitations in laterlife. Demography. 2000;37:73-82.

20. Alley DA, Chang V. The changing relationship of obesity and disability: 1988-2004. JAMA. 2007;298:2020-7.

21. Seeman TA, Merkin SS, Crimmins EM, Karlamangla A. Are disability trends worsening among recent cohorts of older adults? NHANES 1999-2004 versus 1988-1994. Am J Pub Health. 2010;100:100-7.

22. Crimmins EM, Hayward MD, Saito Y. Changing mortality and morbidity rates and the health status and life expectancy of the older population. Demography. 1994;31:159-75.

23. Manton KG, Land K. Active life expectancy estimates for the US elderly population: a multidimensional continuous-mixed model of functional change applied to completed cohorts, 1982-1996. Demography. 2000;37:253-65.

24. Katz S, Ford AB, Moskowitz RW, et al. Studies of illness in the aged: the index of ADL. JAMA. 1963;185:914-9.

25. Burge E, von Gunten A, Berchtold A. Factors favoring a degradation or an improvement in activities of daily living (ADL) performance among nursing home $(\mathrm{NH})$ residents: a survival analysis. Arch Geront Geriatr. 2013;56:250-7. doi:10.1016/j.archger.2012.09.001.

26. Palacios-Ceña D, Jiménez-García R, Hernández-Barrera V, et al. Has the prevalence of disability increased over the past decade (2000-2007) in elderly people? A Spanish population-based survey. JAMDA. 2012;13:136-42. doi:10.2026/jamda.2010.05.077. 
27. Stafford M, Soljak M, Pledge V, Mindell J. Socio-economic differences in the health-related quality of life impact of cardiovascular conditions. Eur J Pub Health. 2011;22:301-5.

28. Brooks R, Rabin NA, de Charro F, et al. The measurement and valuation of health status using EQ-5D: a European perspective. Evidence from the EuroHRQOL BIO MED research programme. New York: Springer; 2003.

29. • Arterburn D, Westbrook EO, Ludman EJ, et al. Relationship between obesity, depression, and disability in middle-aged women. Obes Res Clin Pract. 2012;6:e197-206. doi:10.1016/j.orcp. 2012.02.007. Our study suggests that depression is a predictor of different domains of disability, but that obesity is significantly implicated in work limitations.

30. Claessen H, Brenner H, Drath C, Arndt V. Repeated measures of body mass index and risk of health related outcomes. Eur J Epidem. 2012;27:215-24. doi:10.1007/s10654-012-9669-7.

31. - Alexandre TS, Pires Corona L, Nunes DP, et al. Gender differences in incidence and determinants of disability in activities of daily living among elderly individuals: SABE study. Arch Geront Geriatr. 2012;55:431-7. doi:10.1016/jarchger.2012.04.001. We were one of the few longitudinal studies that did not find obesity to be a predictor of $A D L$ disability.

32. Chakravarty EF, Hubert HB, Krishnan E, et al. Lifestyle risk factors predict disability and death in healthy aging adults. Am J Med. 2012;125:190-7. doi:10.1016/j.amjmed.2011.08.006.

33. SABE. Available at: www.icpsr.umich.edu/icpsrweb/ICPSR/studies/ 3546 Accessed 2/13/13.

34. •- Levine ME, Crimmins EM. The impact of insulin resistance and inflammation on the association between sarcopenic obesity and physical functioning. Obesity. 2012;20:2101-6. doi:10/1038.oby.2012.20. We found an additive effect of obesity,sarcopenia, and sarcobesity in predicting physical functioning. We also found that differences in insulin resistance had an impact on these results.

35. Oh M-K, Jang H, Kim Y-I, et al. Differences in obesity rates between people with and without disabilities and the association of disability and obesity: a nationwide population study in South Korea. J Prev Med Health. 2012;45:211-8. doi:10.3961/jpmph.2012.45.4.211.

36. Braden JB, Young A, Sullivan MD, et al. Predictors of change in pain and physical functioning among post-menopausal women with recurrent pain conditions in the Women's Health Initiative Observational Cohort. J Pain. 2012;13:64-72. doi:10.1016/jpain.2011.10.007.

37. Vagetti GC, Filho VCB, Moreira NB, et al. The prevalence and correlates of meeting the current physical activity for health guidelines in older people: a cross-sectional study in Brazilian women. Arch Geront Geriatr. 2013;56:492-500. doi:10.1016/jarchger. 2012.04.001.

38. Cohen-Mansfield J, Shmotkin D, Hazan H. Homebound older persons: prevalence, characteristic, and longitudinal predictors. Arch Geront Geriatr. 2012;54:55-60. doi:10.1016/jarchger.2011. 02.016.

39. Kim C-H, Luedtke CA, Vincent A, et al. Association between body mass index and response to a brief interdisciplinary treatment program in fibromyalgia. Am J Phys Med Rehabil. 2012;91:57483. doi:10.1097/PHM.ob013e318255665c.

40. Julia C, Ciangura C, Capuron L, et al. Quality of life after Roux-en$\mathrm{Y}$ gastric bypass and changes in body mass index and obesityrelated comorbidities. Diabetes Metab. 2013; http://dx.doi.org/ j.diabet.2012.10.008.

41. Zutler M, Singer JP, Omachi TA, et al. Relationship of obesity with respiratory symptoms and decreased functional capacity in adults without established COPD. Prim Care Respir. 2012;21:194-201. doi:10.4104/pcrj.2012.00028.

42. - Deere KC, Clinch J, Holliday K, et al. Obesity is a risk factor for musculoskeletal pain in adolescents: findings from a population-based cohort. Pain. 2012;153:1932-8. doi:10.1016/pain.2012.06.006. We were one of the few studies to examine different types of pain in adolescents, finding obesity to be a predictor of any pain, knee pain, and chronic regional pain.

43. Ford ES, Li C, Pearson WS, et al. Body mass index and headaches: findings from a national sample of US adults. Cephalalgia. 2008:28:1270-6.

44. Verrotti A, Di Fonzo A, Agostinelli S, et al. Obese children suffer more often from migraine. Acta Pædiatrica. 2012;101:e416-21. doi:10.1111/j.1651-2227.2012.02768.x.

45. •• Halfon N, Larson K, Slusser W. Associations between obesity and comorbid mental health, developmental, and physical health conditions in a nationally representative sample of US children aged 10 to 17. Acad Pediatr. 2013;13:6-13. Using parent-reported difficulty with normal childhood activities as 'disability' in children, we found links between obesity and activity restrictions and several other physical and mental problems.

46. Ranzenhofer LM, Columbo KM, Tanofsky-Kraff M, et al. Binge eating and weight-related quality of life in obese adolescents. Nutrients. 2012;4:167-80. doi:10.3390/nu4030167.

47. Rieger E, Wilfley DE, Stein RI, et al. A comparison of quality of life in obese individuals with and without binge eating disorder. Int J Eat Disord. 2005;37:234-40.

48. Kolotkin RL, Head S, Hamilton M, Tse CK. Assessing impact of weight on quality of life. Obes Res. 1995;3:49-56.

49. - Kimbro RT, Denney JT. Neighborhood context and racial/ethnic differences in young children's obesity: structural barriers to interventions. Soc Sci Med. 2012. doi:10.1016/j.socscimed.2012.09.032. We found significant effects of neighborhood environmental characteristics, such as level of poverty, low levels of education, and high proportion of black residents contributed to obesity in children.

50. Bliddal H, Christensen R. The management of osteoarthritis in the obese patient: practical considerations and guidelines for therapy. Obes Res. 2006;7:323-31.

51. Christensen R, Astrup A, Bliddal H. Weight loss: the treatment of choice for knee osteoarthritis? A randomized trial. Osteoarthr Cartil. 2005;13:20-7.

52. Wren AA, Somer TJ, Wright MA, et al. Self-compassion in patients with persistent musculoskeletal pain: relationship of self-compassion to adjustment to persistent pain. J Pain Symptom Manag. 2012;43:759 70. doi:10.1016/j.jpainsymman.2011.04.014.

53. Pollack KM, Cheskin LJ. Obesity and workplace traumatic injury: does the science support the link? Inj Prev. 2007;13:297-302. doi:10.1136/ip.2006.014787.

54. Reynolds SL, Mcllvane JM. The impact of obesity and arthritis on active life expectancy in older Americans. Obesity. 2008;17:363-9. doi:10.1038/oby.2008.534.

55. •• Vincent HK, Heywood K, Connelly J, Hurley RW. Obesity and weight loss in the treatment and prevention of osteoarthritis. PM R. 2012;4:S59-67. doi:10.1016/j.pmrj.2012.01.005. We presented a model showing the progression from obesity to osteoarthritis, and suggest that weight-loss should precede exercise to prevent joint damage.

56. •• Vincent HK, Raiser SN, Vincent KR. The aging musculoskeletal system and obesity-related considerations with exercise. Ageing Res Rev. 2012;11:361-73. doi:10.1016/j.arr.2012.03.002. We present evidence that weight loss is best achieved by a combination of diet and exercise and that these combined interventions reduced muscle mass loss.

57. Messier SP. Obesity and osteoarthritis disease genesis and nonpharmacologic weight management. Med Clin N Am. 2009;93:145-59. doi:10.1016/j.mcna.2008.09.011.

58. Jiang L, Tian W, Wang Y, et al. Body mass index and susceptibility to knee osteoarthritis: a systematic review and meta-analysis. Joint Bone Spine. 2012;79:291-7. doi:10.1016/j.jbspin.2011.05.015.

59. Guralnik JM, Simonsick EM, Ferrucci L, et al. A short physical performance battery assessing lower extremity function: associations with self-reported disability and prediction of mortality and nursing home admission. J Geront Med Sci. 1994;49:M85-94. 
60. Chun S-W, Kim K-E, Jang S-N, et al. Muscle strength is the main associated factor of physical performance in older adults with knee osteoarthritis regardless of radiographic severity. Arch Geront Geriatr. 2012;56:377-82. doi:10.1016/jarchger.2011.10.013. We found that body mass index, knee pain, and muscle strength were important determinants of physical performance in older adults.

61. Veerhof C, Huisman PA, Barten JA, et al. Factors associated with physical activity in patients with osteoarthritis of the hip or knee: a systematic review. Osteoarthr Cartil. 2012;20:6-12. doi:10.1016/ j.joca.2011.10.006.

62. Himes CL, Reynolds SL. Effect of obesity on falls, injury, and disability. J Am Geriatr Soc. 2012;60:124-9. doi:10.1111/j.15325415.2011.03767.x.

63. - Michaud P-C, Goldman DP, Lakdawalla DN, et al. The value of medical and pharmaceutical interventions for reducing obesity. $\mathrm{J}$ Health Econ. 2012;31:630-43. doi:10.1016/j.jhealtheco.2012.04.006. We compared the relative social value of bariatric surgery vs. weightloss medications and found lower social value in bariatric surgery due to the small number of eligible patients.

64. Park S, Cho S-C, Hong Y-C, et al. Association between dietary behaviors and attention-deficit/hyperactivity disorder and learning disabilities in school-aged children. Psych Res. 2012;198:468-76. doi:10.1016/j.psychres.2012.02.012.

65. Lu C-W, Yang K-C, Chang H-H, et al. Sarcopenic obesity is closely associated with metabolic syndrome. Obes Res Clin Pract. 2012. doi:10.1016/j.orcp.2012.02.003.

66. Desk R, Williams L, Health K. Third report of the National Cholesterol Education Program (NCEP) expert panel on detection, evaluation, and treatment of high blood cholesterol in adults (adult treatment panel III) final report. Circulation. 2002;106:3143.

67. Executive summary of the clinical guidelines on the identification, evaluation, and treatment of overweight and obesity in adults. Arch Intern Med. 1998;158:1855-67.

68. Pilutti LA, McAuley E, Motl RW. Weight status and disability in multiple sclerosis: an examination of bi-directional associations over a 24-month period.

69. World Health Organization. World Health Statistics 2012. Available at: http://www.who.int/healthinfo/EN_WHS2012_Part3.pdf, accessed 2/ $13 / 13$.

70. Reynolds SR, Crimmins EM. Trends in the ability to work among men and women in the older American population. Eur J Ageing. 2010;7:249-56. doi:10.1007/s10433-010-0166-0.

71. Reynolds SR, Crimmins EM, Saito Y. Cohort differences in disease and disability. Gerontologist. 1998;38:578-90.

72. Martin LG, Freedman VA, Schoeni RF, Andreski PM. Health and functioning among baby-boomers approaching 60. J Geront Soc Sci. 2009;64:369-77.

73. Freedman VA, Crimmins E, Schoeni RF, et al. Resolving inconsistencies in trends in old-age disability: report from a technical working group. Demography. 2004;41:417-41. doi:10.1359/ dem.2004.0022.

74. Foss YJ. Vitamin D is the cause of common obesity. Med Hypotheses. 2008;72:314-21.

75. Crimmins EM, Alley D, Reynolds SL, et al. Changes in biological markers of health: older Americans in the 1990s. J Geront Med Sci. 2005;60A:1409-13. 